\title{
Periodicity of atmospheric phenomena occurring in the extreme South of Brazil
}

\author{
Fernando D. Campello*, Jaci M.B. Saraiva, Nisia Krusche \\ Fundação Universidade Federal do Rio Grande, Rio Grande, Brazil
}

Received 25 July 2003; revised 1 December 2003; accepted 9 December 2003

\begin{abstract}
Spectral analysis revealed oscillations associated to atmospheric phenomena in the extreme south of Brazil. Cycles from 36 to 77 days, linked to Madden-Julian Oscillation, from 18 to 28 days, related to the bipolar South Atlantic Convergence Zone-Subtropics mode and 10-day oscillations due to the passage of frontal systems were detected.

(C) 2004 Royal Meterological Society. Published by Elsevier Ltd. All rights reserved.
\end{abstract}

Keywords: Atmospheric oscillations; Spectral analysis; South of Brazil; South Atlantic Convergence Zone; Madden-Julian oscillation

\section{Introduction}

In several regions around the world, periodical phenomena are detected in time series of atmospheric and oceanographic data through the use of spectral analysis techniques (Sultan et al., 1995; Arabelos et al., 1997; Kamata et al., 2002), derived from Fourier's spectral analysis. It considers the decomposition of any sample of a discrete sign as a sequence of sine and cosine waves with different amplitudes and phases (Stull, 1988). The study of the disturbances with a certain periodicity is very useful because the more the periodicity of a phenomenon is known, the more chances there are to predict it and anticipate anomalies related to it. However, there are only a few studies, such as Möller et al. (1996), which use spectral analysis techniques to characterize atmospheric disturbances in the extreme south of Brazil.

It is known that the atmosphere has two important fluctuation modes in low frequencies: inter-annual variations, such as the El Niño/Southern Oscillation (ENSO)

\footnotetext{
* Corresponding author.

E-mail address: fdcampello@yahoo.com.br (F.D. Campello).
} 
phenomenon and intraseasonal variations, such as the 30-60 day Oscillation or the Madden-Julian Oscillation (MJO) (Knutson and Weickmann, 1987). Both can cause substantial changes in the circulation of mid-latitudes in the Southern Hemisphere (Kouski and Kayano, 1994). Paegle et al. (2000) also cite a 22-28 day oscillation mode over the South Atlantic Convergence Zone (SACZ) and the subtropical plains. Moreover, propagation of synoptic scale systems has strong influence on the weather conditions in the extreme south of Brazil (Nobre et al., 1986).

The region of study is located in the subtropical zone, south of Rio Grande do Sul State, extreme south of Brazil. The area stretches over the estuary of the Lagoa dos Patos, where there are three cities: Pelotas in the north, Rio Grande in the west, and São José do Norte, in the east (Fig. 1). The landscape is of coastal and sedimentary plains, with low topography. There are four well-defined seasons in the year. The estuary of the Lagoa dos Patos has intense sea and lake traffic because it houses one of the largest fishing and commercial ports in Brazil. Ships of all sizes navigate the estuary, loaded with fish, and petrol and its derivatives, among other products. It also has great ecological importance because it is used by several species of aquatic animals for reproduction and development (Seeliger et al., 1997). Therefore, good knowledge of the atmospheric circulation patterns in this region is important to help modelers to forecast unpleasant weather conditions, which would cause accidents, and social and environmental damage.

The main objective of this study is to determine, through spectral analysis, the relevant atmospheric cycles found over the extreme south of Brazil and their respective periodicities. An effort is also done in order to link those cycles to well-known periodical atmospheric phenomena that influence the study area, contributing to the understanding of

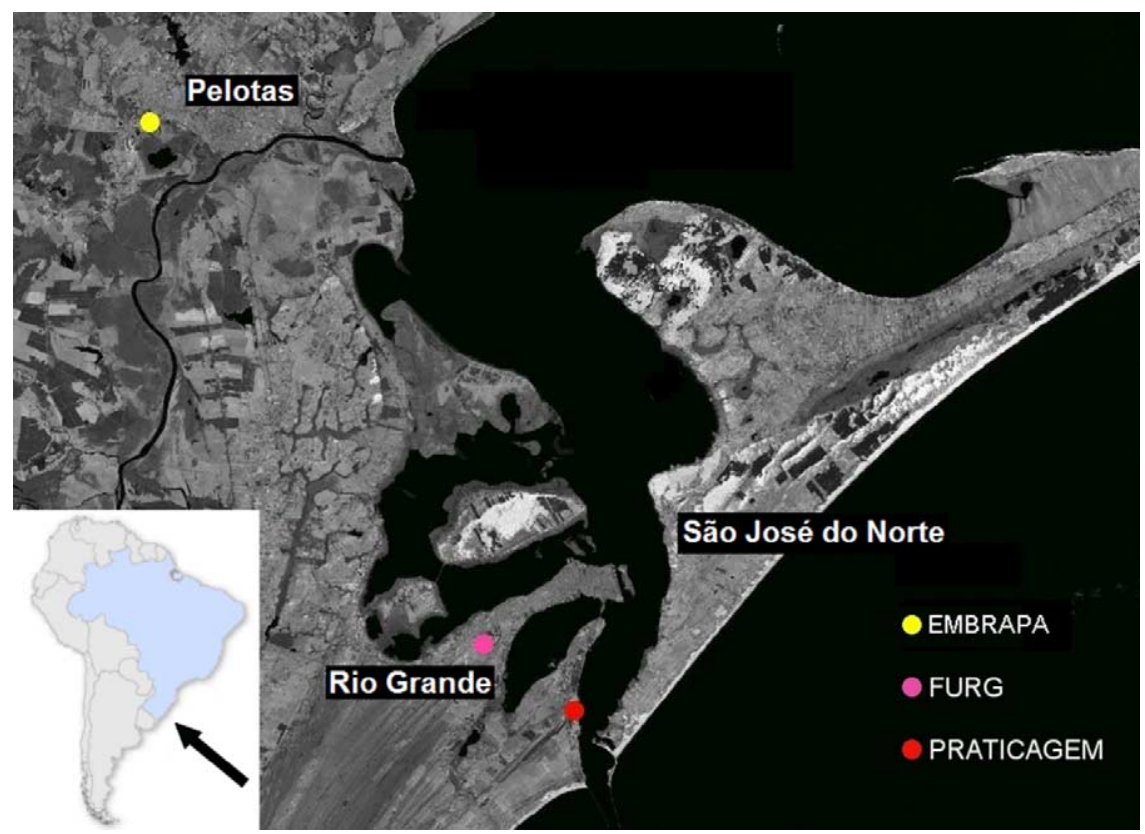

Fig. 1. Location of the area used in the study. 
the atmospheric circulation over this region. In Section 2, data and methodology used in this study are described. Results of spectral analysis are shown and commented in Section 3. Finally, in Section 4, conclusions are presented.

\section{Data and methods}

Data used in this study come from three meteorological stations, two conventional ones, located at the Fundação Universidade Federal do Rio Grande (FURG), and at Empresa Brasileira de Pesquisas Agrícolas (EMBRAPA-UFPel); and an automatic one located near the access channel from the Lagoa dos Patos (Praticagem), shown in Fig. 1.

Data provided by the conventional stations were collected from 1991 to 2000 and are daily average values, calculated according to the regulations of the World Meteorological Organization. Data provided by the automatic station were measured hourly during eight months, from April to December 1999. The wind velocity sensors in this station are located on a tower $25 \mathrm{~m}$ high, whereas the ones in the other stations are $10 \mathrm{~m}$ high. The atmospheric pressure, the air temperature, the relative humidity, the precipitation rate, and the zonal $(u)$ and meridional $(v)$ wind components were analyzed. At the conventional stations, the total number of daily hours of direct insolation, namely the insolation rate, was also analyzed.

The spectral analysis was carried out using Fast Fourier Transform (FFT). The Power Spectral Density was estimated using Welch's averaged periodogram method. This method is based on multiple computation and averaging of the FFT of overlapping data segments. Each of those segments was first detrended and then a Hanning window (50\% overlap) was applied. Emery and Thomson (1998) show the importance of using a window to increase the number of degrees of freedom per espectral estimate, raising the statistical reliability of the analysis. Trethewey (2000) discusses about the importance of window overlapping and cites the 50\% overlap as a commonly used value for the Hanning window in order to prevent the occurrence of either missing or unequally weighted portions of the time signal. A first analysis was carried out using the integral time series for each station. Then, the annual cycle (FURG and EMBRAPA stations) was removed from the series and a second analysis was done, looking at other not so clear periodicities.

\section{Results and discussion}

Spectral analysis applied to integral daily average series (FURG and EMBRAPA stations) clearly showed the predominance of the yearly cycle, with a period of 365.3 days, for the following variables: atmospheric pressure, air temperature, relative humidity, insolation rate, and the zonal wind component. Both stations presented very similar results. The meridional wind component and the precipitation rate showed different behaviors from the other variables. For the first one, the annual cycle was present, but it was weaker than other high frequency oscillations. The strongest energy observed for this component occurred in much lower shorter than the annual one, related to the passage of frontal systems, which will be analyzed later. For the precipitation rate, the annual cycle 
was not found. The absence of strong energy related to the annual cycle in the series of precipitation is a reflex of its behavior in the extreme south of Brazil. The precipitation rate is relatively well distributed throughout the year, according to Diaz et al. (1998). Moreover, Gonzáles and Barros (1996) have shown that the extreme south of Brazil is located in a transition zone between the summer regime (annual cycle, with a maximum in the summer), observed towards to the north-northwest and a winter regime, where precipitation is mainly caused by the passage of frontal systems and by cyclogenesis.

The lowest frequency analyzed for the daily average series was the annual one. According to Stull (1988), because of unresolvable low frequencies (e.g. red-noise) one should not consider frequencies of 3 or less as being reliable (it is important to have at least three waves per sampling period). However, most meteorologists prefer to use at least five or ten waves as the cut off. For this study, ten waves per sampling period were used (10 years), limiting the analysis to the annual oscillation. If the series used were longer (e.g. more than 20 years), we would probably be able to detect the ENSO cycle (time interval of about 3 years) in some of the variables, since some authors (Grimm et al., 1998) emphasize that the ENSO phenomenon have strong influence over the region, specially on the precipitation rate.

A second analysis was carried out after the removal of the annual cycles of FURG and EMBRAPA series. It led to show other spectral peaks, dampened by the high energy of the annual cycle. A semiannual cycle was present in the temperature spectra of both stations (183 days at FURG and 190 days at EMBRAPA). Van Loon (1967) had already noticed a semiannual oscillation for the same variable in the Southern Hemisphere, although for the troposphere. He linked that cycle to differences in the seasonal heating and cooling trends in middle and high latitudes, combined with the special circumstances of nearly equal annual ranges of temperature in the middle troposphere. A 183-day cycle can also be noticed in the precipitation rate of EMBRAPA station and a 130-day oscillation is present in the zonal wind component for both stations. On the other hand, the meridional wind component showed a 135-day cycle at EMBRAPA station only.

Fig. 2 shows the Power Spectral Densities, for atmospheric pressure, insolation, temperature and relative humidity, obtained from the series without the annual cycle. Spectra of those variables presented very small differences between stations. Atmospheric pressure and insolation rate are the most similar ones and there is almost no difference between FURG and EMBRAPA. It was already expected, since both stations are faraway by just $60 \mathrm{~km}$ and most of the atmospheric phenomena recorded in the time series have a spatial scale bigger than that distance. Fig. 3 shows the Power Spectral Densities for meridional and zonal wind components and precipitation rate for both stations. The spectra of those variables are less similar between the stations, although they still show many coincident peaks. Local effects probably easily affect precipitation and wind, resulting in some difference between station's measurements. Considering all the charts, it is possible

Fig. 2. Power Spectral Density for some variables measured at FURG and EMBRAPA station from 1991 to 2000: (a) atmospheric pressure, FURG; (b) atmospheric pressure, EMBRAPA; (c) insolation, FURG; (d) insolation, EMBRAPA (e) temperature, FURG; (f) temperature, EMBRAPA; (g) relative humidity, FURG; (h) relative humidity, EMBRAPA. Values in the abscissa are in days. Red line (in web version) denotes the 95\% confidence limit. 
F.D. Campello et al. / Atmospheric Science Letters 5 (2004) 65-76
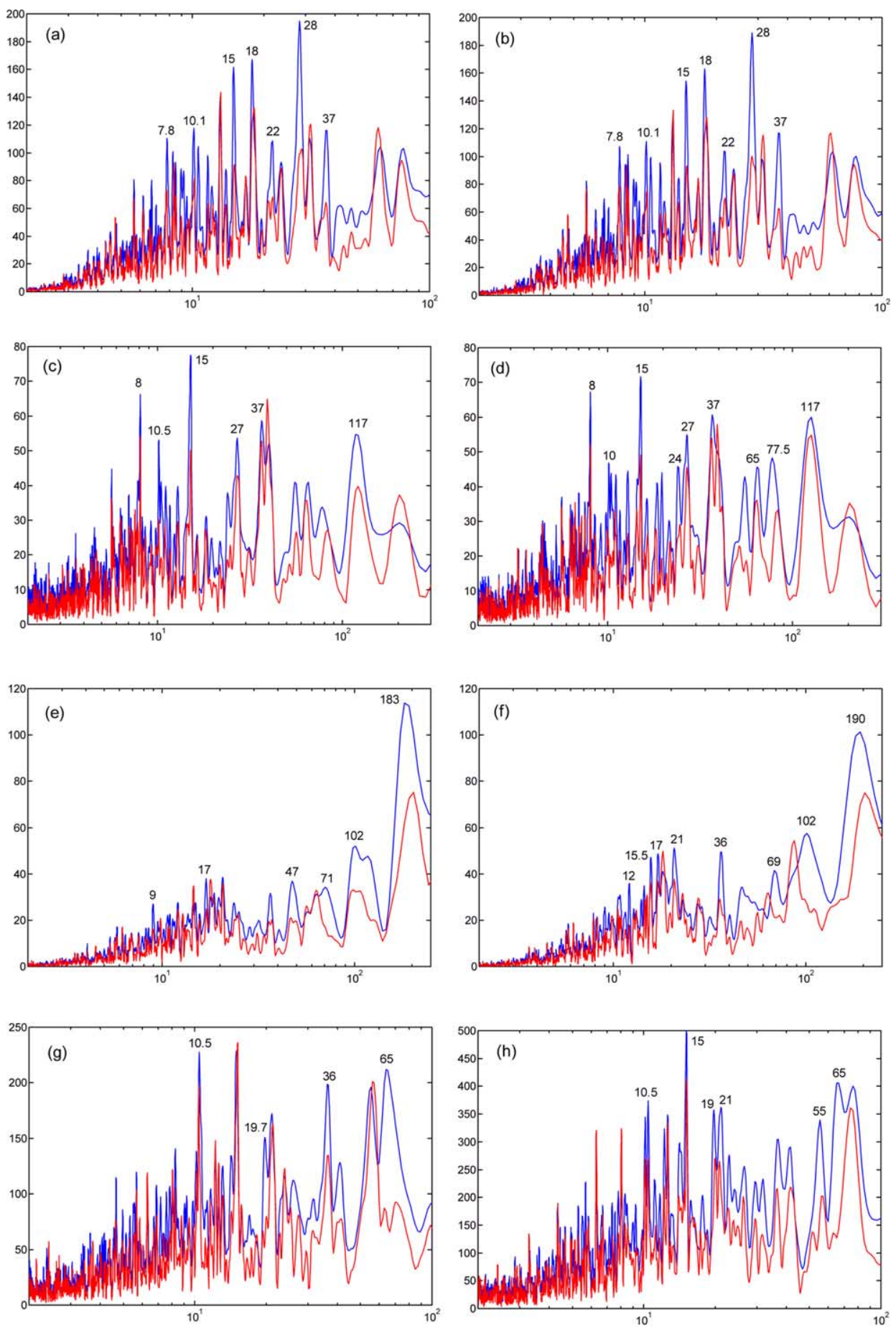

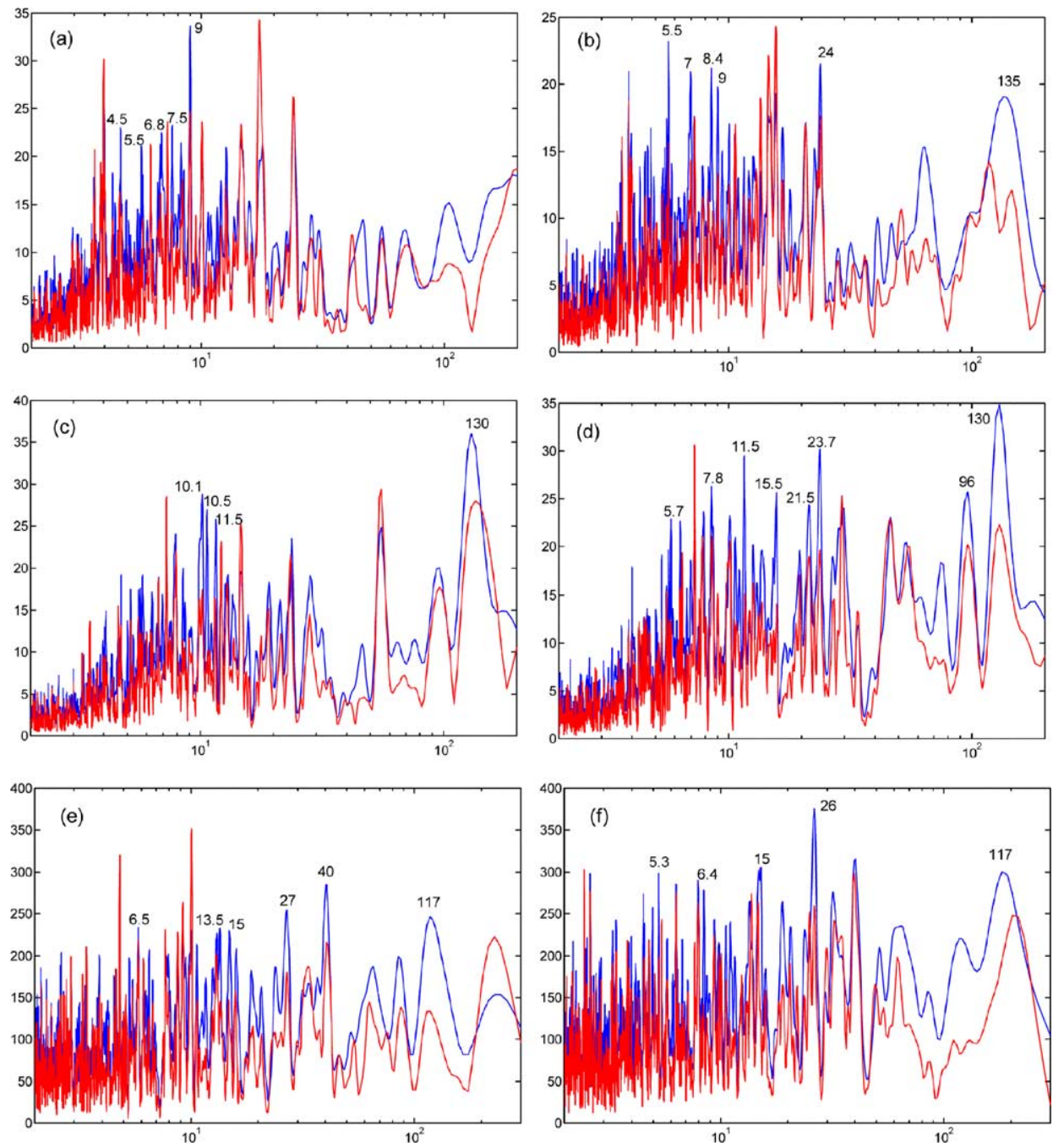

Fig. 3. Power Spectral Density for some variables measured at FURG and EMBRAPA station from 1991 to 2000 : (a) meridional wind component, FURG; (b) meridional wind component, EMBRAPA; (c) zonal wind component, FURG; (d) zonal wind component, EMBRAPA; (e) precipitation, FURG; (f) precipitation, EMBRAPA. Values in the abscissa are in days. Red line (in web version) denotes the $95 \%$ confidence limit.

to observe that temperature presented a strong energy related to lower frequencies, while wind and precipitation showed stronger energy in higher frequencies.

Table 1 displays the significant spectral peaks found for each variable for the series without the annual cycle. Atmospheric phenomena probably associated to each oscillation are also shown. Most of the oscillations can be fitted in three different atmospheric phenomena: the MJO (periods from 36 to 77 days), the bipolar SACZ-Subtropics mode, suggested by Paegle et al. (2000) (periods from 18 to 28 days), and the frontal systems 
Table 1

Significant spectral peaks for each variable (annual cycle removed)

\begin{tabular}{|c|c|c|c|}
\hline Atmospheric phenomenon & Variable & Station & Periodicity (days) \\
\hline \multirow[t]{3}{*}{ Semiannual } & Temperature & FURG & 183 \\
\hline & & EMBRAPA & 190 \\
\hline & Precipitation & EMBRAPA & 183 \\
\hline \multirow{8}{*}{$\begin{array}{l}100-135 \text { days (no phenomenon } \\
\text { associated) }\end{array}$} & Temperature & FURG & 102 \\
\hline & & EMBRAPA & 102 \\
\hline & Insolation & FURG & 117 \\
\hline & Precipitation & FURG & 117 \\
\hline & & EMBRAPA & 117 \\
\hline & Meridional wind component & EMBRAPA & 135 \\
\hline & & FURG & 130 \\
\hline & Zonal wind component & EMBRAPA & 96,130 \\
\hline \multirow[t]{9}{*}{ Madden-Julian Oscillation } & Atmospheric pressure & FURG & 37 \\
\hline & & EMBRAPA & 37 \\
\hline & Temperature & FURG & $36,47,71$ \\
\hline & & EMBRAPA & $36,46,69$ \\
\hline & Relative humidity & FURG & 36,65 \\
\hline & & EMBRAPA & 55,65 \\
\hline & Insolation & EMBRAPA & $37,55,77$ \\
\hline & & FURG & 37 \\
\hline & Precipitation & FURG & 40 \\
\hline \multirow[t]{12}{*}{ Bipolar SACZ-Subtropics mode } & Atmospheric pressure & FURG & $18,22,28$ \\
\hline & & EMBRAPA & $18,22,28$ \\
\hline & Temperature & FURG & 17 \\
\hline & & EMBRAPA & 17,21 \\
\hline & Relative humidity & FURG & 20 \\
\hline & & EMBRAPA & 19,21 \\
\hline & Insolation & FURG & 27 \\
\hline & & EMBRAPA & $19,24,27$ \\
\hline & Precipitation & FURG & 27 \\
\hline & & EMBRAPA & 26 \\
\hline & Meridional wind component & EMBRAPA & 24 \\
\hline & Zonal wind component & EMBRAPA & $21.5,23.7$ \\
\hline \multirow{10}{*}{$\begin{array}{l}\text { Frontal systems (the } 15 \text {-day cycle } \\
\text { is possibly not related } \\
\text { to frontal systems) }\end{array}$} & Atmospheric pressure & FURG & $7.8,10.1,10.5,15$ \\
\hline & & EMBRAPA & $7.8,10.1,10.5,15$ \\
\hline & Temperature & FURG & 9 \\
\hline & & EMBRAPA & $12,15.5$ \\
\hline & Relative humidity & FURG & 10.5 \\
\hline & & EMBRAPA & $10.5,15$ \\
\hline & Insolation & FURG & $8,10.5,15$ \\
\hline & & EMBRAPA & $8,10,13,15$ \\
\hline & Precipitation & FURG & $6.5,13.5,15$ \\
\hline & & EMBRAPA & $4.5,5.3,8.4,15$ \\
\hline
\end{tabular}


Table 1 (continued)

\begin{tabular}{lllc}
\hline Atmospheric phenomenon & Variable & Station & Periodicity (days) \\
\hline Meridional wind component & FURG & $4.5,5.5,6.8,7.5$, \\
& & $8.4,9$ \\
& EMBRAPA & $5.5,7,8.4,9$ \\
& Zonal wind component & FURG & $10.1,10.5,11.5$ \\
& EMBRAPA & $5.7,7.8,10.5,11.5$, \\
& & 15.5
\end{tabular}

activity (periods from 4.5 to 13.5 days). The higher number of peaks is associated to frontal systems. Table 2 shows the three most energetic peaks for each variable. It is interesting to observe that some oscillations, such as the $8-8.4,10.1-10.5,15,26-28$ and 36-37 appear several times among the most energetic ones and should be associated to an important atmospheric phenomena.

A lot of energy peaks with periodicity varying from 4.5 to 13.5 days can be noticed in Figs. 2 and 3 and in Table 1. These oscillations must be a result of the atmospheric variations caused by the passage of frontal systems. Möller et al. (1996) attributed the 11-day oscillations, detected in series of the meridional wind component, to the passage of frontal systems. Castro (1985) related the action of frontal systems to the 9.6- and 12-day oscillations observed in the pressure and wind fields in the southeast of Brazil. Spectral analysis applied to daily pressure data measured in Rio Grande showed oscillations in a period of 6 and 10 days. According to Britto and Saraiva (2001), the monthly average of cold fronts that pass through the area being studied is four per month. It suggests that the precipitation rate in this region is mostly of

Table 2

Three most energetic peaks for each variable

\begin{tabular}{llccc}
\hline Variable & Station & $1^{\circ}$ & $2^{\circ}$ & $3^{\circ}$ \\
\hline Atmospheric pressure & FURG & 28 & 18 & 15 \\
& EMBRAPA & 28 & 18 & 15 \\
Temperature & FURG & 183 & 102 & 21 \\
& EMBRAPA & 190 & 102 & 36 \\
Relative humidity & FURG & 10.5 & 65 & 10.5 \\
& EMBRAPA & 15 & 65 & 37 \\
Insolation & FURG & 15 & 37 \\
Precipitation & EMBRAPA & 15 & 8 & 117 \\
& FURG & 40 & 27 & 117 \\
Meridional wind component & EMBRAPA & 26 & 15 & 4.5 \\
& FURG & 9 & 7.5 & 24 \\
Zonal wind component & EMBRAPA & 5.5 & 8.4 & 10.5 \\
& FURG & 130 & 10.1 & 11.5 \\
\hline
\end{tabular}


frontal origin. Braga and Krusche (2000) showed that the predominant direction of wind during the whole year is northeast, due to the influence of the Southern Atlantic Tropical Anticyclone. However, the passage of frontal systems, due to the advance of the Polar Migratory Anticyclone over the south of Brazil, causes an inversion in the direction of the wind to the south quarter. These influences can be easily noticed in the spectra of wind and precipitation rate, where there is a high number of significant peaks concentrated in periods from 4.5 to 13.5 days. Thought, spectral analysis suggests that all variables seem to be much affected by the passage of frontal systems.

Oscillations with longer periods than the described ones for frontal systems are also observable in Figs. 2 and 3. A 15-day oscillation can be noticed in almost all variables, except in meridional wind component. This oscillation sometimes presents high-energy peaks and shows a period longer than those usually related to frontal systems. No wellknown atmospheric phenomenon was linked to the 15-day cycle in this study. It would be interesting to have more research in order to check the origin of this apparently important oscillation. Cycles with a bit longer periods, between 17 and 28 days, have also occurred in several variables. High energies associated to periods from 26 to 28 days were found in the pressure and precipitation spectra. Such oscillations should be related to a kind of bipolar mode, with opposed signs in the South Atlantic Convergent Zone (SACZ) and in the South Region in Brazil. This situation is suggested by Paegle et al. (2000), who found oscillations between 22 and 28 days, with 22-day meaningful peaks, in data of outgoing longwave radiation (OLR), in a bipolar SACZ-Subtropics mode.

In the same figures, cycles with periods between 36 and 77 days can be noticed. These intraseasonal oscillations must be related to the MJO. Such oscillation is typical of the tropical troposphere, propagates eastward, and happens in a large spectrum, which can vary from 30 to 60 days (Knutson and Weickmann, 1987). However, several authors have shown that MJO can cause substantial changes in the circulation of mid-latitudes in the Southern Hemisphere (Grimm and Silva Dias, 1995). Weickmann et al. (1985) noticed the presence of anticyclones and subtropical cyclones associated with the anomalies of OLR caused by the MJO. These anticyclones and cyclones would move along with the OLR anomalies and would be responsible for affecting the circulation in mid-latitudes. Gonzáles and Barros (1996) carried out spectral analysis for precipitation rate series in several stations in the east and in the northeast of Argentina. They have found oscillations with variable periods between 23 and 45 days, which suggested to be related to MJO. In this study, the 36/37-day oscillation seem especially important. It is not shown in the wind and precipitation spectra only, in which there is a 40-day cycle (FURG station).

The results of spectral analysis applied to the Praticagem station series are shown in Fig. 4, where the abscissa axes represent hours, but the number upon the peaks are presented in days for easier comparison with the other stations. The daily cycle was not removed from the series before the analysis. There are differences between the main energy peaks at the automatic station series and at the conventional stations. These differences are due to the period analyzed in this station (only 1999) and to the higher sampling frequency. Larger differences are related to the presence of a strong daily cycle in temperature and relative humidity and, with less intensity, in the zonal wind component. The one-day oscillation observable in the zonal wind component is a result of the action 

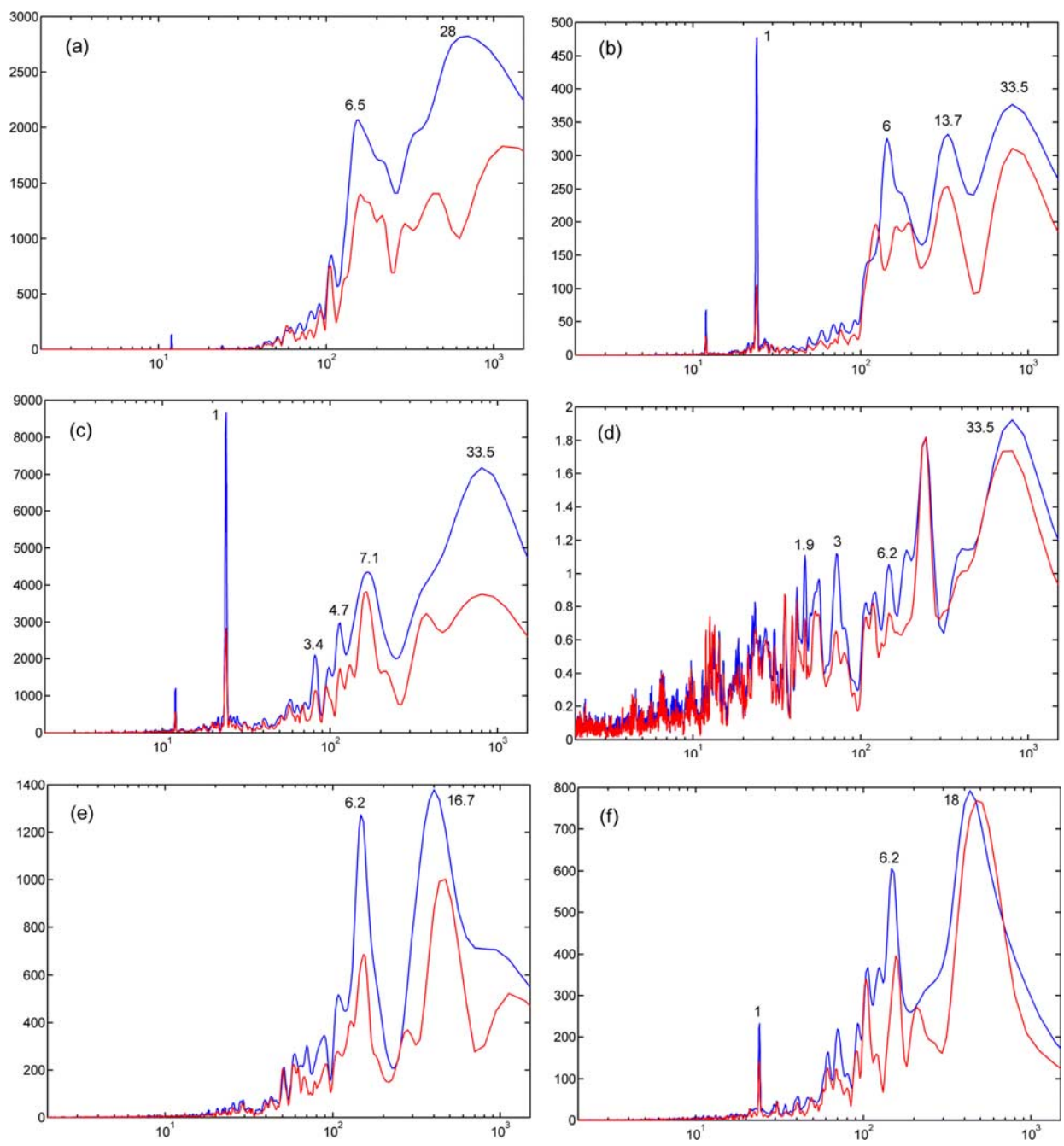

Fig. 4. Power Spectral Density for the variables measured at Praticagem station from April to December 1999. (a) atmospheric pressure; (b) temperature; (c) relative humidity; (d) precipitation; (f) meridional wind component; (g) zonal wind omponent. Values in the abscissa are in hours. Red line (in web version) denotes the $95 \%$ confidence limit.

of sea and land breezes, which move northwest-southeast, in a perpendicular line along the coast. This cycle does not occur for pressure, precipitation, or meridional wind component. An oscillation of 33.5 days was observed for the series of temperature, relative humidity and precipitation, while atmospheric pressure showed a cycle in 28 days. All variables presented peaks between 6 and 7.1 days, caused by the passage of frontal systems. The zonal and meridional components of the wind showed cycles of 18 and 16.7 days, respectively, while temperature presented an oscillation of 13.7 days, not indicated in other variables. 


\section{Conclusions}

The main oscillations that affect the fields of atmospheric variables in the estuary of the Lagoa dos Patos were detected by a spectral analysis technique. The main cycle for pressure, temperature, relative humidity, insolation rate, and zonal wind component corresponded to 365 days (annual), weaker in the wind meridional component and absent in the precipitation. A new analysis, after the removal of the annual cycle of FURG and EMBRAPA stations, emphasized new oscillations. Both stations presented similar results for the spectral analysis of the same variable. Temperature and precipitation (EMBRAPA station) showed semiannual oscillations and a 130-days cycle was present in the wind series. Oscillations related to MJO (36-77 days), to a convective variability in the SACZ region (17-28 days) and to the passage of frontal systems (4.5-13.5 days) were also revealed. Moreover, a strong 15-day cycle, possibly not related to the frontal systems influence became clear in the analysis and could be an object for future studies. Spectral analysis for 1999 carried out with the data provided by Praticagem station showed differences when compared to the other stations, due to the highest sampling frequency and to the shorter period of data series. Nevertheless, like in the other stations, an important oscillation of about 6.2 days, related to the frontal systems, was noticed for all variables. Temperature, relative humidity and precipitation also revealed a 33.5-days peak, probably linked to MJO.

\section{Acknowledgements}

The authors thank the Agência Nacional do Petróleo for the financial support, and EMBRAPA, and Praticagem for providing the data.

\section{References}

Arabelos, D., Asteriadis, G., Contadakis, M.E., et al., 1997. Atmospheric tides in the area of Thessaloniki. J. Geodyn. 23, 65-75.

Braga, M.F.S., Krusche, N., 2000. Padrão de ventos em Rio Grande, RS, no período de 1992 a 1995. Atlântica 22, $27-40$.

Britto, F.P., Saraiva, J.M.B., 2001. Estudo da precipitação associada aos sistemas frontais na cidade do Rio Grande na estação de inverno. Geografia em atos 1, 107-122.

Castro, B.M., 1985. Subtidal response to wind forcing in the South Brazil High during winter. PhD Thesis, University of Miami, Florida, $211 \mathrm{pp}$.

Diaz, A.F., Studzinski, C.D., Mechoso, C.R., 1998. Relationships between precipitation anomalies in Uruguay and Southern Brazil and sea surface temperature in the Pacific and Atlantic oceans. J. Clim. 11, 251-271.

Emery, W.J., Thomson, R.E., 1998. Data Analysis Methods in Physical Oceanography. Pergamon Press, New York, $634 \mathrm{pp}$

Gonzáles, M.H., Barros, V.R., 1996. Aspectos estadisticos del ciclo anual de precipitación y sus anomalias en Argentina Subtropical. Meteorologica 21, 15-26.

Grimm, A.M., Silva Dias, P.L., 1995. Analysis of tropical-extratropical interactions with influence functions of a barotropic model. J. Atmos. Sci. 52, 3538-3555. 
Grimm, A.M., Ferraz, S.E.T., Gomes, J., 1998. Precipitation anomalies in Southern Brazil associated with El Niño and La Niña events. J. Clim. 11, 2863-2880.

Kamata, Y., Matsunami, A., Kitagawa, K., Arai, N., 2002. FFT analysis of atmospheric trace concentration of $\mathrm{N}_{2} \mathrm{O}$ continuously monitored by gas chromatography and cross-correlation to climate parameters. Microchem. J. 71, 83-93.

Knutson, T.R., Weickmann, K.M., 1987. 30-60 day atmospheric oscillations: composite life cycles of convection and circulation anomalies. Mon. Wea. Rev. 115, 1407-1436.

Kouski, V.E., Kayano, M.T., 1994. Principal modes of outgoing longwave radiation and 250 mb circulation for the South American sector. J. Clim. 7, 1131-1143.

Möller, O.O. Jr., Lorenzzetti, J.A., Stech, J.L., Mata, M.M., 1996. The Patos Lagoon summertime circulation and dynamics. Continental Shelf Res. 16, 335-351.

Nobre, C.A., Cavalcanti, I.F.A., Gan, M.A., et al., 1986. Climanálise, Boletim de monitoramento e análise climática: Número especial. INPE, São José dos Campos, 124 pp.

Paegle, J.N., Byerle, L.A., Mo, K.C., 2000. Intraseasonal modulation of South American summer precipitation. Mon. Wea. Rev. 128, 837-850.

Seeliger, U., Odebrecht, C., Castello, J.P., 1997. Subtropical Convergence Environments: The Coast and Sea in the Southwestern Atlantic. Springer, Berlin, 308 pp.

Stull, R.B., 1988. An Introduction to Boundary Layer Meteorology. Kluwer Academic Publishers, Dordrecht, 670 pp.

Sultan, S.A.R., Ahmad, F., Elghribi, N.M., Al-Subhi, A.M., 1995. An analysis of Arabian Gulf monthly mean sea level. Continental Shelf Res. 15, 1471-1482.

Trethewey, M.W., 2000. Window and overlap processing effects on power estimates form spectra. Mech. Syst. Signal Process. 14, 267-278.

Van Loon, H., 1967. The half-yearly oscillations in middle and high southern latitudes and the coreless winter. J. Atmos. Sci. 24, 472-486.

Weickmann, K.M., Lussky, G.R., Kutzbach, J.E., 1985. Intraseasonal (30-60 day) fluctuations of outgoing longwave radiation and $250 \mathrm{mb}$ streamfunction during northern winter. Mon. Wea. Rev 113, 941-961. 